\title{
Renealmia L.f.: aspectos botânicos, ecológicos, farmacológicos e agronômicos
}

NEGRELLE, R.R.B

Laboratório OIKOS, Departamento de Botânica, Universidade Federal do Paraná. Cx. Postal 19031, 81531-990.

Curitiba, Paraná, Brasil.negrelle@ufpr.br

\begin{abstract}
RESUMO: Renealmia L.f. é um gênero de Zingiberaceae com inúmeros usos, entre eles: ornamental, medicinal e alimentício. Visando ressaltar a importância deste gênero como potencial fonte de recursos agroeconômicos apresenta-se esta revisão sobre aspectos botânicos, ecológicos, farmacológicos, e agronômicos. De um universo de 87 espécies formalmente inseridas em Renealmia, registrou-se indicação de uso popular para 18 destas. Em sua maior parte as indicações de uso estiveram associadas a $R$. alpinia, $R$. exaltata e $R$. guianensis englobando, principalmente, os usos ornamental, alimentício e medicinal. Dentre as 14 espécies com indicação de uso popular medicinal, registram-se pesquisas farmacológicas para apenas quatro: $R$. alpinia, $R$. exaltata, $R$. nicolaioides e $R$. thyrsoidea. Entretanto, estas pesquisas evidenciam um amplo espectro de bioatividade, com ênfase na ação anticancerígena e antiofídica, especialmente de $R$. alpinia. Apenas seis espécies foram avaliadas quanto a composição química ( $R$. floribunda, $R$. guianensis, $R$. alpinia, $R$. chrysotricha, $R$. exaltata e $R$. nicolaioides), identificando-se perfil químico que corrobora a potencialidade anticancerígena e antiofídica para os representantes deste gênero. Evidenciou-se grande lacuna no que se refere ao conhecimento científico ou técnico para o cultivo de espécies de Renealmia. Isto pode se configurar num impedimento importante na utilização destas espécies como recurso econômico.
\end{abstract}

Palavras-chave: pacová, planta alimentícia, planta medicinal, planta ornamental, Zingiberaceae.

\begin{abstract}
Renealmia L..f.: botanical, pharmacological and agronomical aspects. The Renealmia L.f. is a genus that belongs to the Zingiberaceae with several applications, including the ornamental, medicinal and food ones. Aiming to emphasize the importance of this genus as a potential agro-economic resource, a review of its botanical, pharmacological and agronomic aspects is presented. From 87 species formally inserted in the Renealmia, 20 were registered with popular uses. In general, these popular uses were associated with $R$. alpinia, $R$. exaltata and $R$. guianensis, mainly including the ornamental, nourishing and medicinal uses. Among 14 species with indication of popular medicinal use, pharmacological studies were registered for only four: R. alpinia, R. exaltata, R. nicolaioides and R. Thyrsoidea. However, these studies show a large bioactivity range, with emphasis in the anti-carcinogenic and antiophidic action, especially for $R$. alpinia. Only six species were analyzed in terms of chemical composition $(R$. floribunda, $R$. guianensis, $R$. alpinia, $R$. chrysotricha, $R$. exaltata and $R$. nicolaioides). Their chemical profiles corroborate the anti-carcinogenic potential for the representatives of this genus. There is a great scientific or technical gap on the cultivation of Renealmia species. This can be an important limiting factor in the use of these species as economical resource.
\end{abstract}

Keywords: red ginger, edible food plant, medicinal plant, ornamental plant, Zingiberaceae.

\section{ASPECTOS BOTÂNICOS \\ Classificação botânica \\ O gênero Renealmia foi descrito em 1782,} por Carl Von Linné Filho, tendo como espécie typus Renealmia exaltata L. f. (Publicado em Supplementum Plantarum 7, 79. 1781[1782]. (Apr 1782) (Suppl. PI.). O gênero está incluído em
Zingiberaceae, família que reúne 53 gêneros e 1.200 espécies pantropicais concentradas especialmente no sudeste da Ásia (Kress, 1990). Esta família, classificada como Monocotiledônea - Comelinidea (Stevens, 2013), inclui apenas representantes herbáceos rizomatosos. 
O autor do gênero, também chamado de Carolus Linnaeus Filius ou Carl von Linné Le Jeune (1741 -1783), foi um naturalista sueco, filho do famoso sistemático de mesmo nome Carl von Linné ou Carolus Linnaeus (1707-1778). O nome deste gênero foi uma homenagem ao botânico francês Paul de Reneaulme (1560-1624) (Merriam-Webster, 2013).

Atualmente, há 151 espécies associadas a Renealmia, sendo 87 destas formalmente aceitas (The Plant List, 2013). Botanicamente (Tropicos, 2013), este gênero está assim classificado:

- Classe: Equisetopsida C. Agardh

- Subclasse: Magnoliidae Novák ex Takht.

- Superordem: Lilianae Takht.

- Ordem: Zingiberales Griseb.

- Família: Zingiberaceae Martinov

- Subfamília: Alpinioideae Link

- Gênero: Renealmia L.f.

Conforme Jannes (2008), a atual classificação das espécies deste gênero é baseada em características morfológicas e dividida de acordo com sua distribuição neotropical e africana. As espécies neotropicais estão divididas nos seguintes grupos de espécies: grupo Renealmia cernua; grupo Renealmia alpinia; grupo Renealmia acreana e grupo Renealmia aromatica. Três espécies isoladas (Renealmia jamaicensis (Gaertn) Horan; $R$. pyramidalis (Lam.) Maas, and R.variegata Maas \& Maas) também estão inseridas entre as espécies neotropicais (Maas \& Maas, 1987; 1990).

$\mathrm{Na}$ África, o gênero é dividido em dois principais complexos de espécies: complexo Renealmia africana e complexo Renealmia congoensis. Adicionalmente, há onze espécies fora destes complexos: Renealmia battenbergiana Cummins ex Baker, R. bracteata de Wild. \& T.Durand, R. cincinnata (K. Schum.) Baker, $R$. densispica J.Koechlin, $R$. engleri K. Schum., $R$.
Iongifolia K. Schum., R. maculata Stapf., R. mannii Hook.f., R. polyantha K. Schum., R. polyantha K. Schum., R. polypus Gagnep., and R. sancti-thomae I.M.Turner. (Jannes, 2008).

\section{Caracterização Botânica}

Renealmia está inserido em Alpinioideae, a segunda maior subfamília de Zingiberaceae, que se distingue morfologicamente das outras subfamílias principalmente por dois atributos: 1 . folhas dísticas de disposição transversa em relação ao rizoma (Figura 1A); 2. flores com dois estaminódios laterais muito reduzidos ou ausentes Figura 1B) (Jannes, 2008).

Renealmia se distingue dos demais representantes da sub-família Alpinoide, assim como de Aframomum K. Schum., o gênero mais próximo, devido a ter a corola mais comprida do que o cálice e pela presença de pelos estelares na lâmina foliar (Maas, 1977; Jannes, 2008) (Figura 1C).

É notável a diversidade de caracteres morfológicos registrada para as espécies de Renealmia, especialmente no que concerne ao porte, especialização dos ramos florais, inflorescências, flores e síndromes florais assim como em relação ao indumento e folhas. Entretanto, não há grande variação na morfologia polínica (Maas, 1977). Quase nada se sabe sobre a variação de outros órgãos e partes como, por exemplo, das sementes (OspinaGonzález, 2011).

Conforme Maas (1977), os representantes de Renealmia são plantas terrestres (1-3 m de altura, podendo chegar a $6 \mathrm{~m}$ ), herbáceas com rizoma de ramificação simpodial, geralmente espesso e de textura quase lenhosa, com raízes carnosas muito finas. Apresentam caules foliáceos eretos dispostos em touceiras densas; folhas dísticas com bainha aberta, lígula, pecíolo às vezes

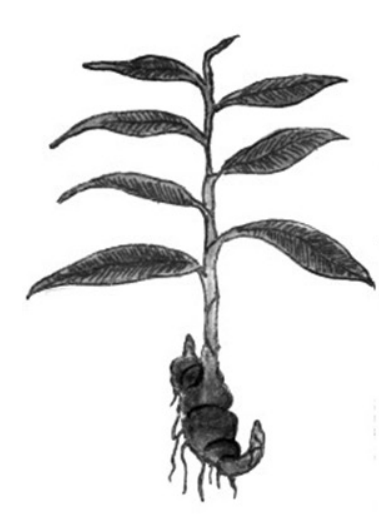

A

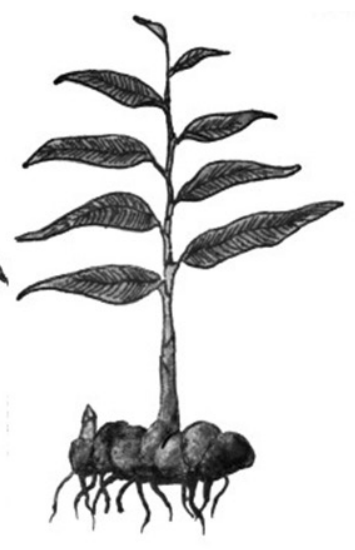

B

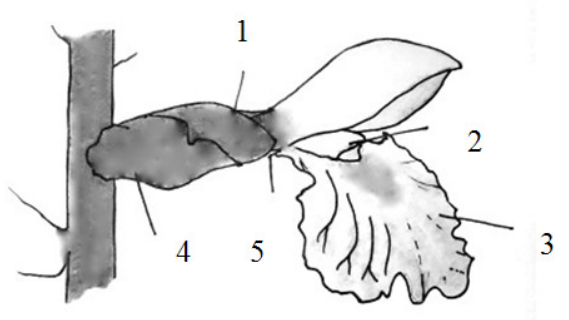

C

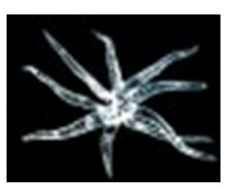

D

FIGURA 1. Renealmia L.f.: A-B) detalhe da disposição foliar dística, transversa ao rizoma; C) detalhe da flor: 1- cálice tubular; 2- antera e estilete; 3- petaloide ereta e labelo 3-lobado; 4- bractéola tubular; 5-corola. D) pelo estelar das folhas. (Fonte: Jannes, 2008). 
pouco evidente e lamina linear peniparalelinérvia orientada verticalmente. A estrutura da bainha é um importante caráter de identificação taxonômica das espécies. As inflorescências podem ser terminais nos ramos eretos ou em escapos florais independentes que emergem da base da touceira. As flores são bissexuadas, zigomorfas, diclamídeas e heteroclamídeas; cálice trímero e gamossépalo; corola trímera, gamopétala. Apresenta dois principais tipos de flores: 1. inteiramente tubular e 2 . base tubular com labelo aberto horizontalmente. Os frutos são geralmente capsulas globosas a elípticas (3-40 mm comprimento) de paredes espessas, com deiscência (loculicida e longitudinal) da base para o ápice. Em algumas espécies, os frutos são coroados por um cálice persistente.

O número de sementes por fruto (1200) também é uma característica taxonômica importante. As sementes (2-5 mm de diâmetro) são elípticas a globosas, amarronzadas, com hilo amarelado bem desenvolvido e amplo arilo lacerado (branco, amarelo ou laranja) (Maas,1977).

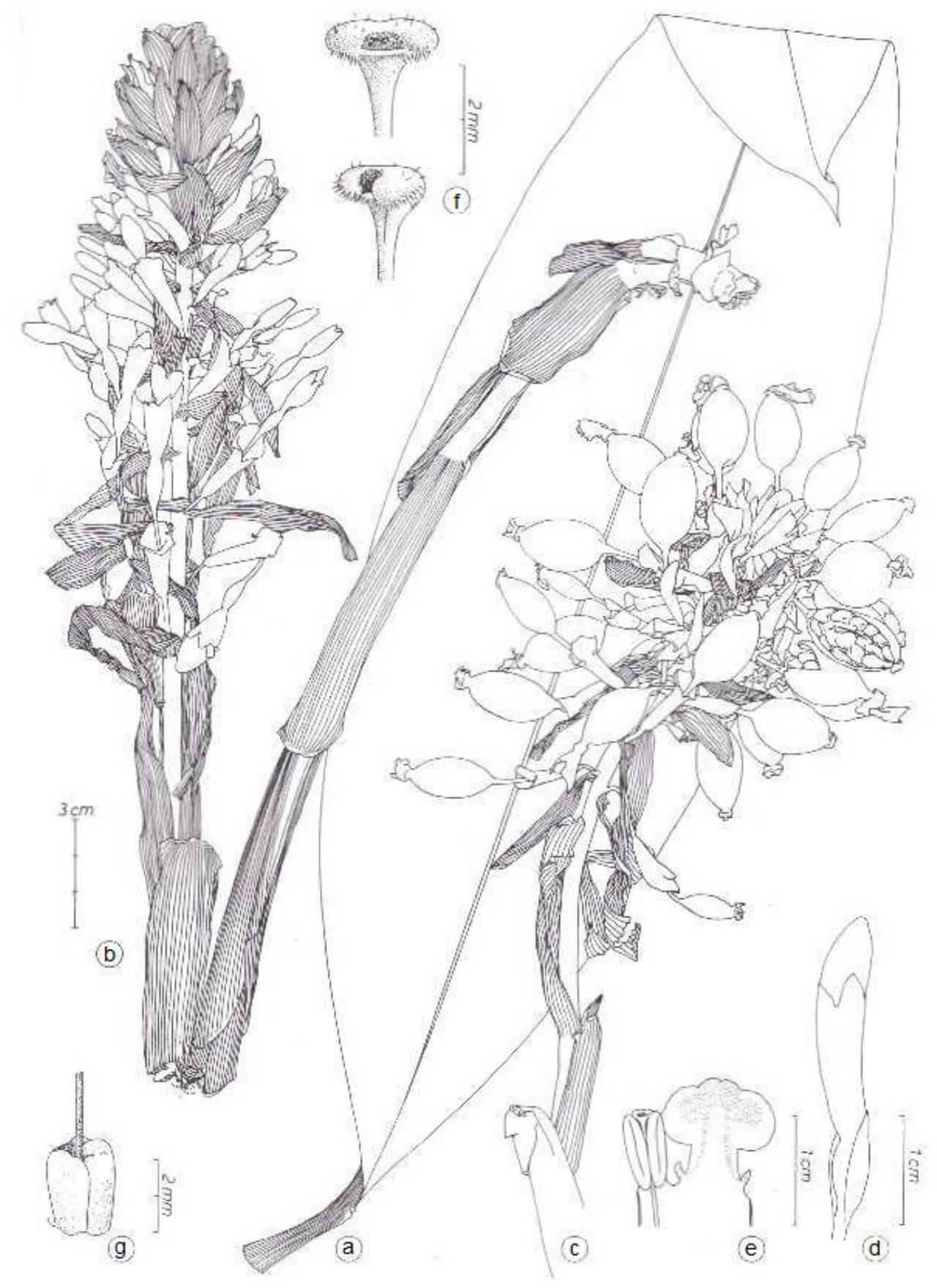

FIGURA 2. Renealmia petasites Gagnep.: a- folha; b- inflorescência; c- infrutescência; d- flor; e- labelo e estame; f- estigma visto de dois lados; g- glândulas nectárias. (Fonte: Maas, 1977). 


\section{Nomes vulgares}

Dependendo do país onde se encontram, genericamente os representantes de Renealmia são popularmente conhecidos por distintos nomes vulgares, incluindo Mishqui panga (Perú), no dialeto quéchua onde "mishqui" significa saborosa e "panga" quer dizer folha (Tabela 1).

\section{ASPECTOS ECOLÓGICOS}

A quase totalidade de espécies do gênero está confinada às regiões de floresta tropical úmida desde o nível do mar até cerca de 2.500 metros.

TABELA 1. Nomes vulgares associados a representantes específicos de Renealmia L.f., em distintos países.

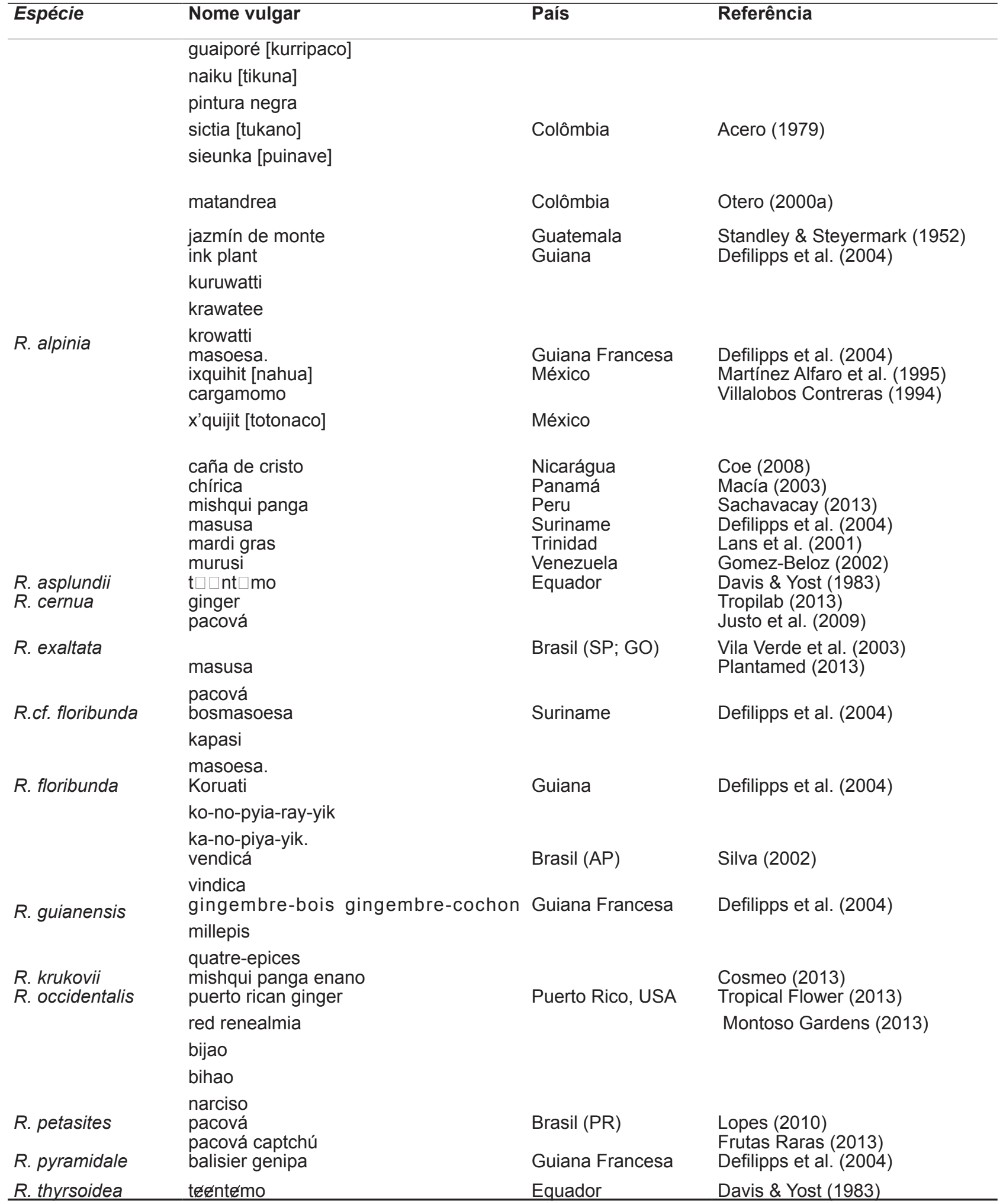

Rev. Bras. Pl. Med., Campinas, v.17, n.2, p.274-290, 2015. 
Nestes ambientes, normalmente ocupam áreas abertas ou margem de rios (Maas, 1977).

A polinização das flores tubulares é feita por beija-flores e das flores de labelo exposto é feita por abelhas (Maas, 1977)

Dentre os poucos registros que existem sobre o processo de dispersão deste gênero, sabe-se que $R$. alpinia apresenta frutos bi-coloridos (vermelhos quando imaturos e roxos quando maduros) característicos de plantas cujas sementes são dispersas por aves diurnas. Entretanto, foram registrados roedores (Oecomys bicolor e O. concolor) como frugívoros oportunistas desta espécie (Bizerril \& Gastal, 1997). Conforme Maas (1977), alguns nomes vulgares associados às espécies de Renealmia são indicativos de potenciais dispersores e/ ou consumidores de frutos: comida de veado (Brasil); tamay de puerco (porco) (México), fruto de mono (macaco) (Colômbia).

\section{Distribuição}

A maioria das espécies de Renealmia é neotropical, distribuindo-se desde o norte do México (ca. $22^{\circ} \mathrm{N}$ lat.), Cuba e Bahamas até o norte da Bolívia e Sul do Brasil (ca. 30॰S lat.), não ocorrendo no Paraguai, Argentina ou Uruguai (Maas, 1977). Cerca de apenas 20 espécies são encontradas na África (Renner, 2004).

Poucos gêneros de Angiospermas compartem este padrão anfiatlântico de distribuição (Renner, 2004). De acordo a Särkinen et al. (2007), este é um padrão muito interessante do ponto de vista biogeográfico evolutivo. Supõe-se que Renealmia se originou na África e colonizou a América do Sul

TABELA 2. Espécies de Renealmia L.f. nativas do Brasil (organizada a partir de Maas \& Maas, 2013) ( ${ }^{*}=$ espécie endêmica do Brasil).

\begin{tabular}{|c|c|c|}
\hline Espécies & Domínio Fitogeográfico & Distribuição geográfica \\
\hline Renealmia acreana Maas & Amazônia & Norte (Pará, Amazonas, Acre) \\
\hline Renealmia alpinia (Rottb.) Maas & Amazônia e Mata Atlântica & $\begin{array}{l}\text { Norte (Roraima, Pará, Amazonas, Rondônia), } \\
\text { Nordeste (Ceará, Bahia), Centro-Oeste (Mato } \\
\text { Grosso, Goiás, Distrito Federal), Sudeste } \\
\text { (Mwinas Gerais, Espírito Santo) }\end{array}$ \\
\hline Renealmia angustifolia K.Schum. ${ }^{*}$ & Mata Atlântica & Sudeste (Espírito Santo) \\
\hline Renealmia aromatica (Aubl.) Griseb. & Amazônia & Norte (Roraima), Centro-Oeste (Mato Grosso) \\
\hline Renealmia brasiliensis K.Schum.* & Mata Atlântica & Sudeste (Minas Gerais, Espírito Santo) \\
\hline Renealmia breviscapa Poepp. \& Endl. & Amazônia & $\begin{array}{l}\text { Norte (Pará, Amazonas, Acre, Rondônia), } \\
\text { Centro-Oeste (Mato Grosso) }\end{array}$ \\
\hline $\begin{array}{l}\text { Renealmia cernua (Sw. ex Roem. \& } \\
\text { Schult.) J.F.Macbr. }\end{array}$ & Amazônia & Norte (Amazonas, Acre, Rondônia) \\
\hline Renealmia chrysotricha Petersen* & Mata Atlântica & Sudeste (Espírito Santo, Rio de Janeiro) \\
\hline Renealmia dermatopetala K.Schum. & Cerrado & Centro-Oeste (Mato Grosso, Goiás) \\
\hline Renealmia floribunda K.Schum. & Amazônia & $\begin{array}{l}\text { Norte (Roraima, Pará, Amazonas, Acre, } \\
\text { Rondônia) }\end{array}$ \\
\hline Renealmia guianensis Maas & Amazônia & $\begin{array}{l}\text { Norte (Amapá, Pará, Amazonas), Nordeste } \\
\text { (Pernambuco, Bahia) }\end{array}$ \\
\hline Renealmia krukovii Maas & Amazônia & Norte (Amazonas, Acre) \\
\hline Renealmia matogrossensis Maas* & Amazônia & $\begin{array}{l}\text { Norte (Pará), Centro-Oeste (Mato Grosso, Mato } \\
\text { Grosso do Sul) }\end{array}$ \\
\hline Renealmia microcalyx Maas \& H.Maas & Amazônia & Norte (Amazonas) \\
\hline Renealmia monosperma Miq. & Amazônia & Norte (Roraima, Pará, Amazonas, Acre) \\
\hline Renealmia nicolaioides Loes. & Amazônia & Norte (Acre) \\
\hline Renealmia petasites Gagnep.* & Mata Atlântica & $\begin{array}{l}\text { Sudeste (Minas Gerais, Espírito Santo, São } \\
\text { Paulo, Rio de Janeiro), Sul (Paraná, Santa } \\
\text { Catarina) }\end{array}$ \\
\hline Renealmia pycnostachys K. Schum.* & Mata Atlântica & Sudeste (Minas Gerais) \\
\hline Renealmia reticulata Gagnep.* & Mata Atlântica & Sudeste (Espírito Santo, Rio de Janeiro) \\
\hline Renealmia thyrsoidea (Ruiz \& Pav.) & Amazônia & Norte (Amazonas, Acre) \\
\hline \multicolumn{3}{|l|}{ Poepp. \& Endl. } \\
\hline Renealmia urbaniana Loes. & Amazônia & Norte (Amazonas, Acre) \\
\hline
\end{tabular}

Rev. Bras. Pl. Med., Campinas, v.17, n.2, p.274-290, 2015. 
por dispersão oceânica de longo alcance durante o Mioceno ou Plioceno (15.8-2.7 milhões de anos atrás), de onde começou uma rápida diversificação, influenciada pela orogênese andina. Aparentemente, a especiação foi praticamente simultânea nos dois lados do Atlântico.

No Brasil, Renealmia é o único gênero nativo de Zingiberaceae (SOUZA \& LORENZI, 2005). Há registro de 21 espécies de Renealmia nativas (7 endêmicas), distribuídas nas distintas regiões do País: Norte (Roraima, Amapá, Pará, Amazonas, Acre, Rondônia), Nordeste (Ceará, Pernambuco, Bahia), Centro-Oeste (Mato Grosso, Goiás, Distrito Federal, Mato Grosso do Sul), Sudeste (Minas Gerais, Espírito Santo, São Paulo, Rio de Janeiro), Sul (Paraná, Santa Catarina) (Maas \& Maas, 2013) (Tabela 2).

\section{Estado de Conservação}

Maas (1977) lista um conjunto de espécies de Renealmia tidas como raras e de ocorrência em ambientes sujeitos a elevado grau de deterioro ambiental sendo, portanto, consideradas como ameaçadas de extinção, a saber: $R$. chiiriquina, $R$. helenae (Panamá); $R$. densiflora (Haiti); R. sylvestris (Jamaica); R. alticola, R. caucana, $R$. chacochlora e R. ferruginea (Colombia); R. oligotricha e $R$. dolichocalyx (Equador); R. pallida e R. wurdackii (Peru). No que concerne às espécies encontradas no Brasil, lista como ameaçadas $R$. braziliensis; $R$. chrysotricha e $R$. reticulata e como provavelmente extinta cita $R$. pycnostachys, espécie representada apenas pelo typus coletado em Minas Gerais.

Minas Gerais $(1997 ; 2008)$ reporta o estado de conservação para duas espécies de Renealmia no contexto brasileiro:

Renealmia brasiliensis K. Schum. = Categoria: vulnerável; Critério: poucas coleções

Renealmia petasites Gagnep. = Categoria: provavelmente extinta; Critério: sem coleta nos últimos 30 anos

\section{USOS ETNOBOTÂNICOS}

Registrou-se indicação de uso popular para 18 espécies de Renealmia, englobando principalmente os usos ornamental, alimentício e medicinal, entre outros. Em sua maior parte, estas indicações de uso estão associadas a $R$. alpinia, $R$. exaltata e R. guianensis. As indicações de uso abrangem todas as partes do organismo vegetal, com ênfase na planta toda, rizoma e sementes.

No que concerne ao uso como planta ornamental, $R$. cernua, $R$. exaltata, $R$. jamaicensis, $R$. mexicana e $R$. occidentalis têm reconhecida importância comercial tanto como flores de corte, plantas envasadas, rizomas ou sementes (Ayala-
Silva et al., 2007; Miceli et al., 2008; Aloha Tropicals, 2013; Montoso Gardens, 2013; Tropical Flower, 2013; Tropilab, 2013).

No que tange ao uso alimentício, as folhas frescas de algumas espécies de Renealmia são empregadas como envoltório para cozinhar peixe (patarashca) e, quando secas e moídas, servem como condimento (Rainforest, 2013). Especificamente, registra-se para $R$. alpinia o emprego das folhas frescas como envoltório de tamales e empanadas, Ihes conferindo um sabor peculiar e picante (Macía, 2003). As folhas aromáticas de $R$. battenbergiana são usadas como condimento na preparação de vários pratos como sopas e molhos, enriquecendo seu sabor. Também são utilizadas industrialmente para aromatizar óleos vegetais (Ofosu et al., 2012).

Os frutos frescos de R. petasites e R. alpinia são considerados comestíveis, especialmente pela presença de arilo em suas sementes (Otero et al. 2000a; Macía, 2003; Frutas Raras, 2013). As sementes marrom-amareladas de $R$. exaltata são utilizadas como condimento e corante alimentício, especialmente em pratos com arroz (Tropilab, 2013). As sementes de $R$. petasites também são usadas como tempero ou condimento (Frutas Raras, 2013). O óleo obtido das sementes de $R$. alpinia tem emprego culinário (Maas, 1977; Acero, 1979; Villalobos Contreras, 1994; Martínez Alfaro et al., 1995; Macía, 2003).

Há uma ampla variedade de uso medicinal popular associada a espécies de Renealmia, que incluem o emprego da planta toda, folhas, flores, frutos e/ou sementes associados a distintos modos de utilização como infusos, decocto, banhos, extratos e pastas, conforme detalhado a seguir.

$O$ infuso das folhas e rizomas de $R$. alpinia, $R$.guianensis ou de $R$. monosperma é considerado abortifaciente (Defilipps et al., 2004).

A ingestão oral do produto da decocção ou infusão das folhas de $R$. alpinia, $R$. asplundii, $R$.brasiliensis, $R$. cincinnata ou $R$. guianensis é tida como de efeito analgésico contra dores de cabeça e musculares (Milliken \& Albert, 1996; Silva, 2002; Coe, 2008; Coelho-Ferreira, 2009; Valadeau et al., 2009; Patiño et al., 2012).

O decocto das folhas e rizomas de $R$. alpinia administrado oralmente é tido como de efeito antiácido para gestantes (Coe, 2008).

$O$ infuso das sementes trituradas de $R$. exaltata é indicado para o tratamento antibruxismo (Justo et al., 2009).

O decocto das folhas de $R$. alpinia (Defilipps et al., 2004) assim como a infusão das sementes de $R$. petasites são referidos como de efeito antidisentérico (Lopes, 2010).

Os frutos de $R$. alpinia são tidos como de 
efeito antiemético e antinauseante (Maas, 1977; Acero, 1979; Villalobos Contreras, 1994; Martínez Alfaro et al., 1995; Macía, 2003).

O banho com o decocto dos ramos e folhas de $R$. guianensis e $R$. monosperma é citado para o tratamento antifadiga (Defilipps et al., 2004).

Para tratamento antiflatulência, indica-se o uso das inflorescências de $R$. guianensis e $R$. monosperma (Defilipps et al., 2004) assim como a decocção das folhas e rizomas de $R$. alpinia e das sementes e rizomas de $R$. exaltata (Plantamed, 2013).

O suco do fruto de $R$. floribunda tem emprego medicinal como antifúngico (Defilipps et al., 2004).

A inalação do vapor da decocção de $R$. cf. floribunda assim como o xarope ou suco do rizoma de $R$. alpinia são considerados como de efeito antigripal (Defilipps et al., 2004).

A ingestão oral do rizoma de $R$. alpinia macerado e fervido em água é tida de efeito antihemorrágico, sendo especialmente benéfica em casos de hemorragias ginecológicas (Valadeau et al., 2009).

Há registro histórico do uso de $R$. dominguensis como anti-hemorroidas, pela civilização Maia (Usher,1974).

O suco dos frutos de $R$. floribunda é citado como indicado para tratamento de antiherpes genital e aftas (Defilipps et al., 2004).

O infuso das folhas de $R$. alpinia é citado como de uso popular como antihipertensivo (Defilipps et al., 2004).

O infuso das sementes de $R$. petasites é citado como medicamento popular anti-infertilidade (Lopes, 2010).

Tanto o decocto das folhas e rizomas de $R$. brasiliensis como de $R$. alpinia (Coe, 2008) são considerados como de efeito anti-inflamatório.

O decocto dos rizomas de $R$. floribunda, $R$. guianensis ou $R$. monosperma é tido como de efeito antimalarial (Defilipps et al., 2004).

A ingestão oral do decocto e/ou banhos com o extrato etanólico de rizomas de $R$. alpinia são considerados de efeito antiofídico (Otero, 2000a). O suco elaborado com frutos de $R$. alpinia e Costus scaber é indicado no tratamento antiofídico veterinário, para cães (Lans et al., 2001). A pasta feita com água e folhas e rizomas triturados de $R$. alpinia, $R$. asplundii, $R$. brasiliensis, $R$. guianensis ou de $R$. thyrsoidea é colocada sobre picada de cobras, especialmente Bothrops atrox e B. asper. O chá das folhas destas espécies é utilizado para aliviar o inchaço provocado pela picada de cobra (Davis \& Yost, 1983; Silva, 2002; Patiño et al., 2012).

O decocto de frutos e folhas de $R$. alpinia é usado em banhos para cães como antipediculose
(Lans, 2001).

Banhos com o decocto das folhas e rizomas de $R$. alpinia, $R$. asplundii, $R$. cincinnata, $R$. floribunda, $R$. guianensis, $R$. monosperma ou $R$. pedicelaris (Altschul, 1973; Milliken \& Albert, 1996; Zhou et al., 1997; Defilipps et al., 2004; Patiño et al., 2012) assim como o extrato alcoólico de $R$. alpinia (Otero et al., 2000a) são tidos como de efeito antipirético. Folhas maceradas de $R$. thyrsoides são referenciadas como para aliviar os sintomas febris da malária (Schultes \& Raffauf, 1990).

O suco do fruto de $R$. floribunda é utilizado para tratamento antipruridos (Defilipps et al., 2004).

O uso dos rizomas $R$. pyramidale macerados e misturados com rum ou vermute é tido como de efeito antirreumático (Defilipps et al., 2004). São apontados também com este efeito: a infusão das folhas e rizomas de $R$. brasiliensis (Milenar Terapias, 2013); das sementes de $R$. petasites (Cesarino \& Negrelle, 2012) e o decocto ou garrafada com rizomas e folhas de $R$. exaltata (Vila Verde et al., 2003).

A ingestão assim como banhos com o decocto das folhas de $R$. alpinia e de $R$. guianensis são citados como de efeito calmante (Silva, 2002; Defilipps et al., 2004).

O infuso de flores de $R$. guianensis (SILVA, 2002) assim como o decocto, xarope e suco do rizoma de $R$. alpinia (Defilipps et al., 2004) são tidos como cardiotônico.

A ingestão do infuso de folhas, sementes, flores e/ou rizomas de $R$. alpinia, $R$. asplundii, $R$. brasiliensis, $R$. cincinnata, $R$. exaltata, $R$. guianensis, $R$. orinocensis e $R$. petasites é apontada como de efeito carminativo (Milliken \& Albert, 1996; Silva, 2002; Vila Verde et al., 2003; Defilipps et al., 2004; Lopes, 2010; Cesarino \& Negrelle, 2012).

As sementes de R.exaltata são referidas como de ação cicatrizante (Plantamed, 2013).

O banho com o decocto de rizoma e folhas de $R$. guianensis ou de $R$. monosperma são considerados como de ação desinfetante de feridas associadas à Leishmaniose (Defilipps et al., 2004).

A polpa dos frutos de $R$. orinocensis é utilizada como inseticida para exterminar formigas cortadeiras (Atta sp.) (Van Andel, 2000)

O infuso da flor de $R$. guianensis é considerado como de efeito laxante (Silva, 2002).

O suco dos frutos de $R$. exaltata (Tropilab, 2013) assim como o decocto dos rizomas de $R$. alpinia (Defilipps et al., 2004) são citados como medicamentos oftálmicos.

O infuso de sementes de $R$. petasites é tido como vermígugo (Lopes, 2010).

Enquanto a uso místico, cita-se os banhos com decocto das folhas de $R$. alpinia como complemento do ritual Ayahuasca (Sachavacay, 
2013) assim como o banho com decocto das folhas de $R$. guianensis para tirar feitiçaria, mau-olhado e trazer sorte no amor e na profissão (Silva, 2002).

Uma porção do talo herbáceo foliar de $R$. alpinia é colocada na cova de semeadura de milho, como controle biológico associado a este cultivo, visando afugentar roedores e aves frugívoras (Macía, 2003).

A partir da maceração dos frutos maduros roxos e das raízes amarelas das espécies de Renealmia obtêm-se corantes naturais (Rainforest, 2013). Especificamente, cita-se esta possibilidade a partir do exocarpo carnoso do fruto de $R$. alpinia (Maas, 1977; Acero, 1979; Villalobos Contreras, 1994; Martínez Alfaro et al., 1995; Macía, 2003).

$R$. battenbergiana é reportada como flavorizante industrial, especialmente na indústria farmacêutica, cosmética e de perfumaria (Ofosu et al., 2012).

\section{COMPOSIÇÃO QUÍMICA}

Poucas espécies inseridas no gênero Renealmia tem sido objeto de estudo quanto à sua composição química. O conhecimento disponível sobre a composição química destas espécies é apresentado a seguir:

\section{R. alpinia}

O óleo das sementes de $R$. alpinia foi analisado quanto a presença de glicerídeos e esteróis, evidenciando-se triacilglicerol como o principal constituinte glicerídico. A análise dos ácidos graxos (GLC) revelou a presença de 14 compostos. O fracionamento da porção não saponificável apontou a presença de esteróis, metilesterois e álcool triterpênico. As análises GCMS e GLC evidenciaram colesterol, campesterol, estigmasterol, $\beta$-sitosterol, como principais moléculas esterólicas (Lognay et al., 1989).

Outro estudo da composição química das sementes de $R$. alpinia revelou a presença de $14 \%$ de óleo-resina marrom-escura. $\mathrm{Na}$ análise desta, combinando-se técnicas de cromatografia e espectrometria, evidenciou-se entre os compostos voláteis (4.4\% da oleoresina), a predominância de monoterpenos ( $\beta$-pineno $22.3 \%$, limoneno $18.4 \%$ e $\beta$-felandreno $38.0 \%$ ). O fracionamento da óleoresina revelou a presença de $\beta$-caroteno, nerolidol e manol. O principal constituinte (45\%) foi identificado como 8(17),12(E)-labdadieno-15,16-dial (Lognay et al., 1991).

A pesquisa de Lognay et al.(1991) também reporta a presença de $\beta$-caroteno em $R$. alpinia.

Na sequência, Zhou et al. (1997) isolaram, a partir do extrato foliar de $R$. alpinia, dois novos diterpenos labdanos (11-hydroxy-8(17),12(E)- labdadieno-15,- 16-dial 11,15-hemiacetal e 16-oxo8(17), ácido 12(E)-labdadieno-15-oico) assim como o diterpeno 8(17),12(E)-labdadieno-15,16-dial, já conhecido.

Yang et al. (1999), a partir do extrato foliar de $R$. alpinia, isolaram dois diterpenoides já conhecidos assim como um novo labdano diterpenoide $\left(\mathrm{C}_{20} \mathrm{H}_{30} \mathrm{O}_{4}\right)$.

De acordo a Defilipps et al. (2004), R. alpinia contém protocianina.

Boukouvalas et al. (2006) reportam que o labdano diterpenoide, previamente isolado por Yang et al. (1999) para R. alpinia, possui estrutura idêntica ao diterpenoide $(+)$-zerumin $B$, isolado por $\mathrm{Xu}$ et al. (1996) para a planta chinesa Alpinia zerumbet (Figura 3).

O óleo essencial das folhas de $R$. alpinia foi analisado por GC e GC-MS, evidenciando-se 35 constituintes com predominância de $\beta$-cariofileno $(22.9 \%)$, $\beta$-pineno (12.0\%), espatulenol $(10.0 \%)$, alloaromadendreno (8.3\%), $\varsigma$-cadineno $(5.3 \%)$ e germacreno $\mathrm{D}(5.1 \%)$. Trinta e dois componentes foram identificados no óleo de ramos, com predominância de alloaromadendreno (15.7\%), espatulenol (12.1\%), germacreno D (9.9\%), $\beta$-pineno (9.5\%), g-cadineno (9.1\%), epi-cubebol $(5.3 \%)$ and $\beta$-cariofileno (5.1\%). Dentre os trinta e oito constituintes identificados no óleo do fruto, $\beta$-felandreno (60.4\%) e $\beta$-pineno (19.8\%) resultaram como os principais compostos (Maia et al., 2007) (Tabela 3)

Silva (2008) isolou 2,4-di-hidroxi-6(fenileteno)-benzoato de metila e 2,4-di-hidroxi-6(feniletano)-benzoato de metila, a partir do extrato hexânico da folha de $R$. alpinia.

Alarcón et al. (2008) evidenciaram a presença de cumarinas no tecido foliar de plântulas de $R$. alpinia obtidas a partir de propagação in vitro.

Marchese (2009), a partir do fracionamento químico do extrato hexânico de folhas de $R$. alpinia, isolou dois compostos inéditos para a espécie:
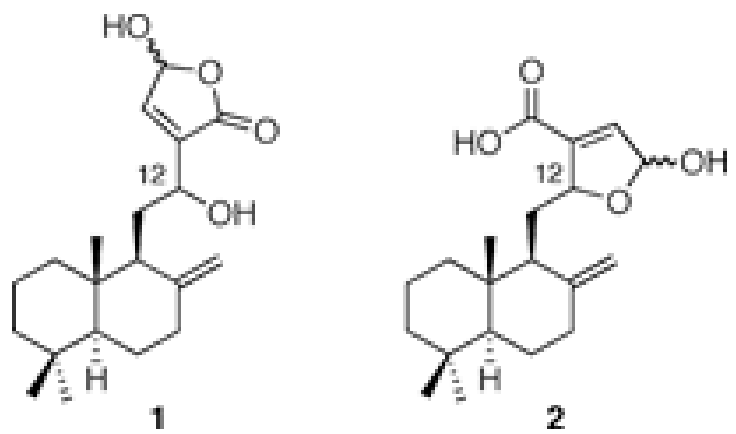

FIGURA 3. Estruturas químicas originalmente assignadas para (+)-zerumin B (1) e para o diterpenoide isolado de $R$. alpinia (2) (Fonte: Boukouvalas et al.,2006). 
TABELA 3. Constituintes voláteis identificados no óleo de distintas partes de $R$. alpinia

\begin{tabular}{|c|c|c|c|}
\hline constituintes & folha & $\begin{array}{l}\text { \% óleo } \\
\text { ramo }\end{array}$ & fruto \\
\hline a-thujene & 0,1 & & \\
\hline a-pinene & 1,7 & 1,4 & 3,9 \\
\hline sabinene & 0,4 & 0,1 & 0,4 \\
\hline b-pinene & 12 & 9,5 & 19,8 \\
\hline myrcene & & & 1,4 \\
\hline para-mentha-1(7),8-diene & & & 0,9 \\
\hline a-phellandrene & & & 0,9 \\
\hline limonene & 0,3 & 0,2 & \\
\hline b-phellandrene & & 0,3 & 60,4 \\
\hline g-terpinene & 0,1 & & \\
\hline trans-pinocarveol & 0,1 & 0,2 & \\
\hline trans-pinene hydrate & & & 0,1 \\
\hline trans-verbenol & 0,1 & $\operatorname{Tr}$ & \\
\hline pinocarvone & 0,1 & 0,1 & \\
\hline cis-pinocamphone & & 0,1 & \\
\hline terpinen-4-ol & 0,1 & & 0,1 \\
\hline a-terpineol & & & 0,2 \\
\hline myrtenal & 0,1 & 0,1 & \\
\hline myrtenol & 0,1 & 0,1 & \\
\hline trans-pinocarvyl acetate & & $\mathrm{Tr}$ & \\
\hline a-terpinyl acetate & & & 0,2 \\
\hline a-copaeno & 0,2 & 0,4 & 0,1 \\
\hline$\beta$-bourboneno & 0,5 & & \\
\hline$\beta$-caryophylleno & 22,9 & 5,1 & 0,9 \\
\hline a-humuleno & 2,7 & 0,5 & 0,1 \\
\hline allo-aromadendreno & 8,3 & 15,7 & 2,2 \\
\hline trans-cadina-1(6), 4-dieno & 0,8 & & \\
\hline y-muuroleno & & 1,4 & 1,8 \\
\hline germacreno d & 5,1 & 9,9 & 0,1 \\
\hline biciclogermacreno & 2,1 & & 0,5 \\
\hline epi-cubebol & & 5,3 & \\
\hline trans- $\beta$-guaieno & & & 0,3 \\
\hline a-muuroleno & 0,8 & & \\
\hline Y-cadineno & 5,3 & 9,1 & 1,5 \\
\hline cubebol & 1 & 3,9 & \\
\hline ঠ-cadineno & 0,8 & & 0,6 \\
\hline cis-calameneno & 0,4 & 0,9 & 0,1 \\
\hline (e)-nerolidol & 2,4 & 2,1 & 0,7 \\
\hline espatulenol & 10 & 12,1 & 0,8 \\
\hline oxido cariofileno & 8,6 & 0,4 & 0,2 \\
\hline viridiflorol & & 1 & \\
\hline humuleno epoxide ii & 1,6 & 1 & \\
\hline 1-epi-cubenol & 0,5 & 1 & 0,2 \\
\hline cariofila-4(14),8(15)dien-5-a-ol & 0,6 & & \\
\hline pi-a-cadinol & 0,4 & 1 & 0,2 \\
\hline epi-a-muurolol & 0,3 & 2,5 & \\
\hline a-muurolol & 0,3 & 2,3 & \\
\hline a-cadinol & 1 & 0,3 & 0,2 \\
\hline total & 91,4 & 88 & 98,8 \\
\hline
\end{tabular}

2,4-di-hidroxi-6-(fenileteno)-benzoato de metila e do 2,4-di-hidroxi-6-(feniletano)-benzoato de metila, elucidados por meio de técnicas espectrométricas de ressonância magnética nuclear de uma dimensão (1D) (1H e 13C) e bidimensional (2D) (COSY, HSQC e HMBC) e de infra-vermelho (IV).

\section{R. chrysotrycha}

A partir da análise das folhas de $R$. chrysotrycha, Kaplan et al. (2000) reportam o isolamento do álcool sesquiterpênico identificado como ledol conjuntamente com três outros compostos (aromadendreno, cis-calameneno e palustrol).

\section{R. exaltata}

A partir de sementes de $R$. exaltata, Sekiguchi et al. (2001) isolaram três novos labdanos diterpenoides, as pacovatinas $\mathrm{A}\left(\mathrm{C}_{20} \mathrm{H}_{30} \mathrm{O}_{3}\right), \mathrm{B}$ $\left(\mathrm{C}_{20} \mathrm{H}_{30} \mathrm{O}_{4}\right)$ e C $\left(\mathrm{C}_{20} \mathrm{H}_{28} \mathrm{O}_{4}\right)$ (Figura 4).

Sekiguchi et al. (2002) reportam o isolamento, a partir também de sementes de $R$. exaltata, de dois novos diarilheptanoides, as renealtinas $\mathrm{A}\left(\mathrm{C}_{21} \mathrm{H}_{24} \mathrm{O}_{7}\right)$ e $\mathrm{B}\left(\mathrm{C}_{21} \mathrm{H}_{24} \mathrm{O}\right)$ (Figura 5).

Gowravaram et al. (2007) reportam o isolamento de dois diarilheptanoides, as renealtinas Ae B (Figura 6), a partir de sementes de $R$. exaltata.

\section{R. floribunda}

Um dos trabalhos pioneiros da caracterização da composição química de representantes de Renealmia foi relativo ao óleo essencial obtido a partir de folhas de $R$. floribunda, apresentada em Luz et al. (1984). Neste, evidenciou-se a predominância do monoterpeno $\beta$-pineno, entre outros compostos (Tabela 4).

TABELA 4. Constituintes do óleo essencial das folhas de Renealmia floribunda

\begin{tabular}{lc}
\hline Composto & $\%$ óleo \\
\hline$\beta$-Pineno & 27,89 \\
myrtenal & 5,74 \\
trans-pinocarveol & 5,11 \\
a-pineno & 2,60 \\
limoneno & 1,52 \\
terpenyl acetato & 0,68 \\
$p$-cymeno & 0,37 \\
peryllaldehydo & 0,22 \\
1.8-cineol & 0,19 \\
carvona & 0,16 \\
isobornyl acetato & 0,15 \\
$\beta$-bourboneno & 0,15 \\
trans- $\beta$-bergamoteno & 0,14 \\
verbenona & 0,12 \\
trans-carveol & 0,11 \\
linalol & 0,10 \\
a-thujona & 0,10 \\
\hline (Fonte: Luz et al., 1984)
\end{tabular}




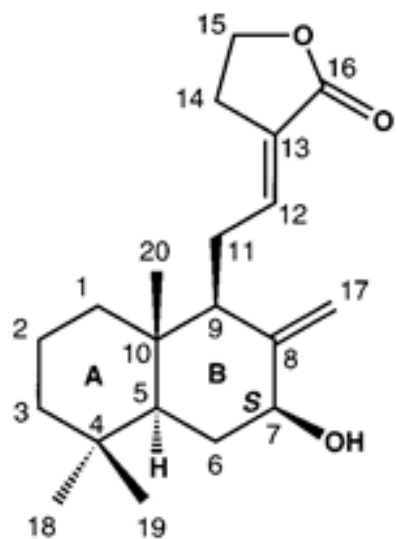

pacovatina A

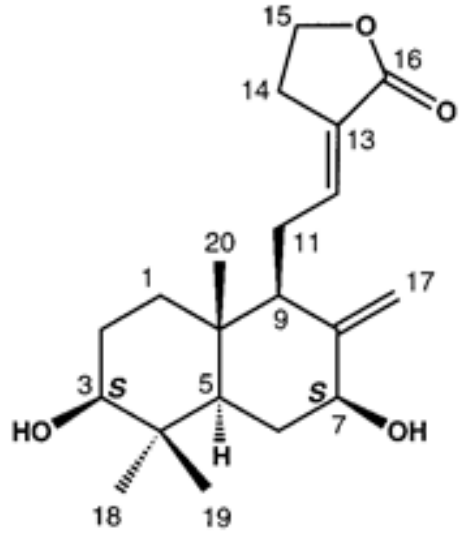

pacovatina $B$

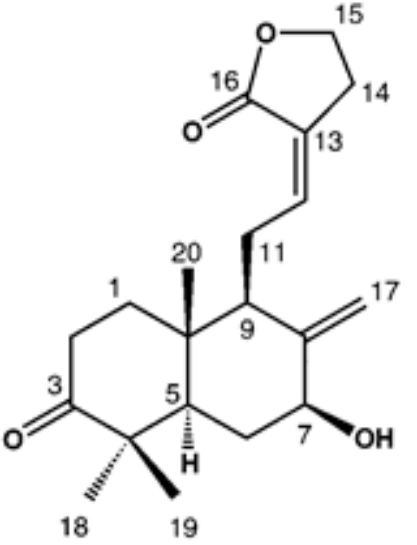

pacovatina $\mathrm{C}$

FIGURA 4. Labdanos diterpenoides identificados em R. exaltata (Fonte: Sekiguchi et al., 2001)

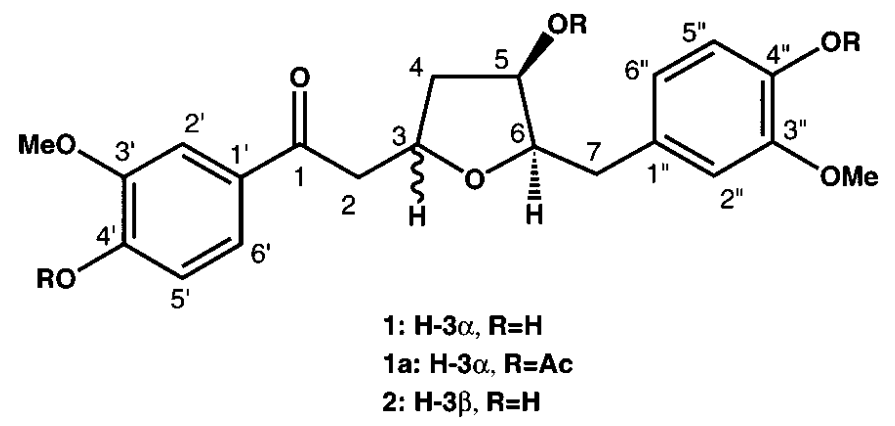

FIGURA 5. Renealtinas A (1) e B (2) identificados em R. exaltata (Fonte: Sekiguchi et al., 2002)<smiles>COc1cc(C[C@@H]2O[C@@H](CC(=O)c3ccc(O)c(OC)c3)C[C@@H]2O)ccc1O</smiles>

renealtin $\mathrm{A}, 1$<smiles>COc1cc(C[C@@H]2O[C@@H](CC(=O)c3ccc(O)c(OC)c3)C[C@@H]2O)ccc1O</smiles>

renealtin $\mathrm{B}, \mathbf{2}$

FIGURA 6. Diarilheptanoides identificados em R. exaltata (Fonte: GOWRAVARAM et al., 2007)

Defilipps et al. (2004) reiteram que o principal constituinte do óleo essencial de $R$. floribunda é o $\beta$-pineno.

\section{Renealmia guianensis}

Ramiandrasoa et al. (1986) isolaram o terpeno labda-8(17),12-diene-15,16-dial de folhas de $R$. guianensis.

\section{R. mexicana}

Segundo Miceli et al. (2008), R. mexicana é fonte de curcuminoides.

\section{R. nicolaioides}

A partir do extrato metanólico do rizoma de $R$. nicolaioides, foram isoladas três novas dihidrochalconas preniladas, as nicolaioidesinas A, B, e C (1-3). Também foi identificado o produto natural 5- estirilfuraona-2- ácido metil éster carboxílico (4), juntamente com os compostos, 2'-hidroxi-4',6'-dimetoxichalcona (5), (+/-) -5-hidroxi7-metoxiflavanona (6), (+/-) -5-hidroxi-7,4'dimetoxiflavanona e panduratin A (Gu et al., 2002).

De acordo a Jung \& Lee (2008), as nicolaioidesinas A, B e C reportadas em Gu et al. 


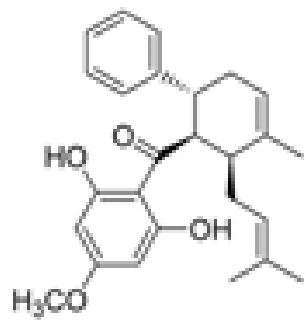

panduratin $\mathrm{A}$

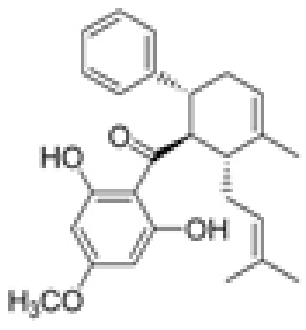

nicolaioidesin A

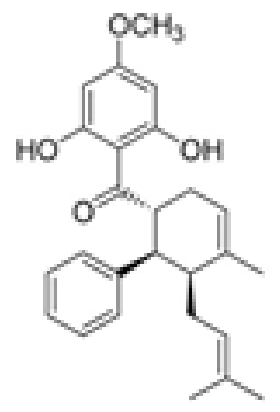

nicolaioidesin B

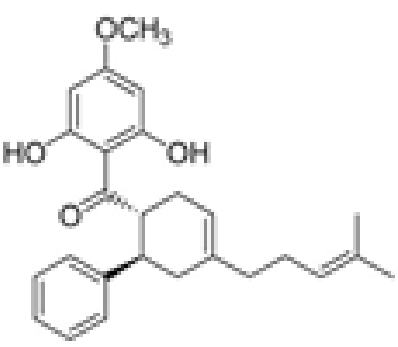

nicolaioidesin C

FIGURA 7. Dihidrochalconas naturais, conforme Jung \& Lee (2008)

(2002) são isômeros de panduratin A (Figura 7).

\section{Renealmia sp.}

Leclercq et al. (2000) reportam a análise do óleo essencial das folhas de espécie não identificada de Renealmia encontrada no Peru, citando $\beta$-pineno, 1,8-cineol e cânfora como constituintes mais expressivos (Tabela 5)

\section{ASPECTOS FARMACOLÓGICOS}

De um universo de 87 espécies formalmente reconhecidas, incluindo pelo menos $14 \mathrm{com}$ indicação de uso popular medicinal, registram-se pesquisas farmacológicos para apenas quatro destas espécies: $R$. alpinia, $R$. exaltata, $R$. nicolaioides e $R$. thyrsoidea.. Entretanto, estas pesquisas evidenciam um amplo espectro de bioatividade, com ênfase na

TABELA 5. Constituintes do óleo essencial de folhas de Renealmia sp.

\begin{tabular}{lc}
\hline Composto & $\%$ \\
$\beta$-pineno & 31,9 \\
1,8 cineol & 21,3 \\
cânfora & 10,5 \\
metil (E)-cinnamato & 6,7 \\
$\alpha$-pineno & 4,8 \\
a-terpineol & 3,4 \\
canfeno & 3 \\
limoneno & 3 \\
borneol & 2,8 \\
linalol & 2,2 \\
p-cimen-8-ol & 2,2 \\
terpineno-4-o1 & 2 \\
dihidroedulam & 1,7 \\
trans-pinocarveol & 1,6 \\
Hidrato de canfeno & 1,6 \\
isobornil acetato & 1,3 \\
não identificado & 0,1 \\
\hline
\end{tabular}

(Fonte: Leclercq et al., 2000) ação anticancerígena e antiofídica, especialmente de $R$. alpinia, conforme detalhado a seguir.

\section{Analgésico}

Patiño et al. (2012), registraram efeito analgésico da fração de metanol obtida das folhas de $R$. alpinia em ratos submetidos a injeção intraperitoneal de agente causador de dor (2-fenil1,4-benzoquinona ou fenilquinona). A dose de 100 $\mathrm{mg} / \mathrm{kg}$ determinou até $98 \%$ de proteção contra o estímulo doloroso, efeito comparável a dose de 75 $\mathrm{mg} / \mathrm{kg}$ de ibuprofeno.

\section{Anticancerígeno}

Zhou et al. (1997), utilizando labdanos diterpenoides isolados do extrato das folhas de $R$. alpinia, identificaram atividade antitumoral in vitro, em ensaio com células de carcinoma pulmonar.

Gu et al. (2002) identificaram os compostos 2'-hidroxi-4',6'-dimetoxichalcona e (+/-)-5-hidroxi7-metoxiflavanona, isolados de $R$. nicolaioides, como indutores de quinona redutase, uma enzima anticarcinogênica, em teste com células de hepatoma de ratos.

Kang \& Pezzuto (2004) reiteram a capacidade de $R$. nicolaioides de induzir a quinona redutase, dada a presença de chalconas em sua composição química.

Cuendet et al (2006), avaliando mais de 2600 extratos de plantas, reforçam a capacidade de representantes de Renealmia induzir a quinona redutase, sendo ativos na prevenção anticâncer.

Segundo Cragg et al. (2006), devido aos seus constituintes químicos lábdano diterpênicos, $R$. alpinia é considerada como planta anticancerígena, com potencial para tratamento de leucemia.

De acordo a Gowravaram et al (2007), as renealtinas $\mathrm{A}$ e $\mathrm{B}$ evidenciadas em $R$. exaltata são diarelheptanoides caracterizados por um anel tetrahidrofurano. A presença destes compostos químicos confere à esta espécie uma alta potencialidade de ação antitumoral.

Conforme Majumdar et al. (2011), os compostos naturais panduratin A e nicolaiodesin 
C identificados como ciclohexenil chalconas, encontrados nos rizomas de $R$. nicolaioides, inibem a catepsina, uma protease da cisteína que possui relação fundamental com o desenvolvimento, invasão e metastase de tumores humanos.

\section{Antichagásico}

Rangel (2010) identificou atividade do extrato diclorometânico do rizoma de $R$. alpinia sobre formas epimastigotas de Trypanosoma cruzi $\left(\mathrm{IC}_{50}=\right.$ $50 \mu \mathrm{g} / \mathrm{mL}$ ). Esta atividade foi próxima ao benznidazol ou benzonidazol $($ Rochagan $\AA$, Rodanil ()$)(I C=46 \mu \mathrm{g} /$ $\mathrm{mL}$ ), medicamento referência do teste e usado para a quimioterapia específica da doença de Chagas.

\section{Antifúngico}

Segundo Rangel (2010), o extrato diclorometânico do rizoma de $R$. alpinia foi ativo

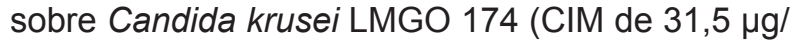
$\mathrm{mL}$ ), C. parapsilosis ATCC 22019 e C. glabrata LMGO 44 (ambos com CIM de $125 \mu \mathrm{g} / \mathrm{mL}$ ). Igualmente registrou-se atividade deste extrato sobre Cryptococcus neoformans var. gattii (CIM de $32,5 \mu \mathrm{g} / \mathrm{mL}$ ) e C. neoformans var. neoformans (CIM de $7,81 \mu \mathrm{g} / \mathrm{mL})$.

Silva (2008) evidenciou $100 \%$ de inibição do desenvolvimento de Trichophytum rubrum com a utilização do extrato hexânico de folhas de R.alpinia (10 e $20 \mathrm{mg} / \mathrm{mL}$ ).

\section{Anti-inflamatório}

Segundo Wohlmuth et al. (2010), a presença dos compostos diarilheptanoides nos representantes de Renealmia Ihes confere potente propriedade anti-inflamatoria.

\section{Antileishmaniose}

Marchese (2009) identificou a atividade do extrato hexânico das folhas de R.alpinia sobre formas promastigotas de Leishmania (Leishmania) amazonenses $\left(\mathrm{IC}_{50}=40,58 \mu \mathrm{g} / \mathrm{mL}\right)$. O extrato hexânico de folhas juntamente com rizomas desta mesma espécie apresentou atividade sobre formas promastigotas de Leishmania (Leishmania) chagasi $\left(\mathrm{IC}_{50}=22,81 \mu \mathrm{g} / \mathrm{mL}\right)$.

Valadeau et al. (2009) evidenciaram interessante atividade leishmanicida sobre Leishmania (Leishmania) amazonenses testando o extrato etanólico do rizoma de $R$. alpinia (IC50 < $10 \mu \mathrm{g} / \mathrm{mL}$ ).

Rangel (2010) registrou a atividade do extrato diclorometânico do rizoma de $R$. alpinia sobre as formas amastigotas de $L$. (L.) chagasi e $L$. (L.) amazonensis, com $\mathrm{IC}_{50}$ de 6,03 e $11,58 \mu \mathrm{g} / \mathrm{mL}$, respectivamente. Para as células de mamíferos, esse extrato apresentou $\mathrm{IC}_{50}$ de 235,38 $\mu \mathrm{g} / \mathrm{mL}$, com índice de seletividade de 39 para $L$. (L.) chagasi.

\section{Antimalárico}

De acordo a Gowravaram et al (2007), a presença de renealtinas $A$ e $B$ evidenciadas em $R$. exaltata confere à esta espécie uma alta potencialidade de ação antimalárica.

Valadeau et al. (2009) evidenciaram que o extrato etanólico do rizoma de $R$. thyrsoidea apresentou boa atividade contra Plasmodium falciparum resistente a cloroquina $\left(\mathrm{IC}_{50}<10 \mu \mathrm{g} / \mathrm{mL}\right)$.

\section{Antiofídico}

Otero et al. (2000b) evidenciaram que o extrato etanólico de rizomas de $R$. alpinia apresentou $100 \%$ de capacidade neutralizadora, dentro de $48 \mathrm{~h}$, do efeito letal do veneno de Bothrops atrox quando injetado em cobaias (0.5-4.0 mg/rato; $L_{50}=99.3$ $\mathrm{mg}$ ).

Otero et al. $\left(2000_{c}\right)$ reportam que o extrato etanólico de rizoma de $R$. alpinia apresentou

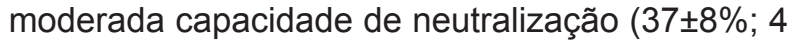
$\mathrm{mg} /$ rato) do efeito hemorrágico gerado pelo veneno de $B$. atrox.

Núñez et al. (2004a), utilizando extrato etanólico de folhas de $R$. alpinia, evidenciaram neutralização parcial do edema $(66 \pm 3 \% ; 100 \mu \mathrm{g} /$ cobaia) e $100 \%$ redução dos efeitos defibrinante e coagulante causados pelo veneno de $B$. asper.

Núñez et al. (2004b) registraram total neutralização dos venenos dos ofídios Lachesis muta, Crotalus durissus cumanensis e Micrurus mipartitus com injeção intrapeitoral de extrato etanólico de $R$. alpinia em cobaias pré-incubadas $\left(1,5 L D_{50}\right)$

Fernández et al. (2010) avaliaram a capacidade inibidora dos extratos etanólicos de folhas e rizomas e frações obtidas por cromatografia em coluna de $R$. alpinia, cultivada in vitro, sobre os efeitos hemolítico indireto, proteolítico e coagulante induzidos pelo veneno de Bothrops asper. A atividade hemolítica indireta foi maiormente inibida pela fração $7-8(47,3 \pm 2,20 \%)$, seguida pelos extratos do rizoma $(32,6 \pm 6,90 \%)$ e folhas $(24,2 \pm 4,43 \%)$ de origem in vitro e folhas ex vitro $(16,2 \pm 3,88 \%)$. A atividade proteolítica foi fortemente inibida pelos extratos foliares tanto produzidos in vitro como ex vitro, sem diferenças significativas. Contra a atividade coagulante, foi registrada uma maior neutralização com o extrato de rizomas produzidos in vitro $(81,73$ $\pm 9,94 \mathrm{~s}$ ). Foi descartado um potencial mecanismo de ação proteolítico sobre o veneno de $B$. asper dado que não se produziram variações nos padrões eletroforéticos do veneno. Segundo os autores, estes resultados viabilizam a aplicação de $R$.alpinia como coadjuvante no tratamento de acidente ofídico e sustentam a utilidade da micro propagação para a produção massiva de componentes ativos. 
Patiño et al. (2012) evidenciaram que o extrato etanólico das folhas de $R$. alpinia apresentou efeito inibitório total (100\%) do efeito letal do veneno de $B$. asper, em experimento in vivo com ratos tratados previamente com $225 \mathrm{mg} / \mathrm{kg}$ deste extrato. Registraram também efeito inibitório deste extrato sobre a atividade hemolítica indireta assim como sobre a atividade coagulante e atividade proteolítica sobre azocaseína, associadas ao acidente ofídico.

\section{Antioxidante}

De acordo a Defilipps et al. (2004), R. alpinia é fonte de protocianina, antioxidante natural que previne a peroxidação lipídica e homeostase.

\section{Antiparasitário}

Conforme Gowravaram et al (2007), as renealtinas $\mathrm{A}$ e $\mathrm{B}$ evidenciadas em $R$. exaltata confere à esta espécie uma alta potencialidade de ação anti-helmíntica.

Xavier et al. (2008) não evidenciaram atividade antiparasitária de $R$. exaltata frente a Haemonchus contortus em ovinos. Para este teste, foram utilizadas sementes $R$. exaltata secas, pulverizadas e veiculadas em gel de hidroxietil celulose (HEC), nas concentrações de $50 \mathrm{mg} / \mathrm{Kg}$ e $100 \mathrm{mg} / \mathrm{Kg}$ de peso corpóreo, administradas via oral a ovinos.

\section{Moluscicida}

Santos \& Sant'Ana (2000) registraram que o extrato crú de folhas de $R$. exaltata apresentou significante atividade moluscicida contra Biomphalaria glabrata (adulto $\mathrm{DL}_{50}=28,03 \mathrm{ppm}$; ovo $\mathrm{DL}_{50}=21,67 \mathrm{ppm}$ )

\section{Toxicidade}

Patiño et al. (2012) não evidenciaram qualquer tipo evidência de toxicidade ou morte de ratos cobaias, durante 14 dias de tratamento com extrato etanólico de folhas de $R$. alpinia, com dose de $2000 \mathrm{mg} / \mathrm{kg}$.

\section{ASPECTOS AGRONÔMICOS}

Há uma grande lacuna no que se refere a conhecimento científico ou técnico sobre o cultivo de espécies de Renealmia. Em sites comerciais de venda de plantas envasadas, sementes ou rizomas de Renealmia spp., registram-se orientações simples de cultivo. Dentre estes, Rainforest (2013) indica que as espécies de Renealmia são de fácil cultivo mas requerem condições úmidas e solos férteis. De acordo a Hawaiian Tropical Plants (2013), estas plantas crescem bem mesmo quando envasadas e preferem solos levemente ácidos e com alto teor de matéria orgânica. Podem ser cultivadas a pleno sol ou meia sombra, devendo ser mantido solo úmido. $R$. petasites tem sido regularmente cultivada por pequenos agricultores na região litorânea do Paraná (Mun. Guaratuba), a partir de formação de mudas por propagação vegetativa (rizomas). Este cultivo é em associação com outros cultivos locais, especialmente nos entremeios de plantios de banana. Não há registro de requerimentos especiais para o cultivo desta espécie (Cesarino, 2013).

No entanto, segundo Macía (2003), especialmente $R$. alpinia apresenta germinação seminal pouco exitosa e propagação dependente da continua geração de brotos a partir do rizoma. Frente a esta dificuldade de produção de mudas via germinação ou propagação vegetativa, Alarcón et al. (2008) propõem o cultivo in vitro como alternativa para a produção da espécie. Segundo estes autores, a adição de 6- Bencilaminopurina (3 mg/L) promove a propagação desta espécie vegetal, com taxa de velocidade de multiplicação (TVM) de 1.39 brotos/semana, enquanto que a indução de tecido indiferenciado é favorecida pela exposição dos explantes foliares a combinação de 2,4-D (2 mg/L) y $B A(1 \mathrm{mg} / \mathrm{L})$.

\section{COMÉRCIO}

Os principais segmentos de comercialização de espécies de Renealmia são o de plantas ornamentais e de plantas medicinais e menos expressivamente, o alimentício. Vários sites de venda de plantas ornamentais oferecem espécies de Renealmia, num contexto de mercado internacional. Dentre estes, o Hawaiian Tropical Plant (2013) oferece representantes deste gênero por US $\$ 17,00$ a unidade. As variedades "freed red" e "yellow spike" de $R$. cernua são também comercializadas como plantas ornamentais, tanto envasadas como na forma de unidade reprodutiva (rizomas), com preços entre US\$12,00 a 25,00 (Aloha Tropicals, 2013). O site $E^{*}$ Species Tropical Seeds oferece o cento de sementes de $R$. aromática a US $\$ 7,95$. Os rizomas de $R$. exaltata são oferecidos pelo Tropilab (2013) a US\$ 9,75 cada.

De acordo com Miceli et al. (2008), $R$. mexicana é comercializada como planta ornamental no sul do México. Entretanto, o mercado desta planta é problemático dada a sua baixa capacidade de propagação e germinação em condições naturais.

O comércio representante de Renealmia no segmento de plantas medicinais parece ser mais regionalizado ou em nível local. Segundo Zaroni et al. (2004), R. exaltata - A identificação desta espécie deve ser confirmada, dado que a mesma não é nativa no Brasil (ver Maas \& Maas, 2012) - tem sido produzida no Mun. Pinhais (PR) e comercializada como planta medicinal. Entretanto, 
através de análise de amostras deste cultivo evidenciou-se baixa qualidade microbiológica deste produto especialmente devido a presença de enterobactérias e outras bactérias Gram negativas assim como contagens elevadas de aeróbios, bolores e leveduras. Os frutos de $R$. petasites cultivada por agricultores da Colônia Castelhanos (mun. Guaratuba, PR), são comercializados como recurso medicinal (Cesarino, 2013). $R$. floribunda, apesar de ser considerada planta rara, é comercializada como planta medicinal no Suriname, a partir de coleta extrativista (Van Andel \& Havinga, 2008). Alguns sites de venda de produtos naturais e plantas medicinais também oferecem espécies de Renealmia. Na Milenar Terapias (2013), anuncia-se pacote de $80 \mathrm{~g}$ de folhas e rizomas desidratados de $R$. brasiliensis, marca comercial Flor do Campo, por $\mathrm{R} \$ 6,20$.

As folhas aromáticas de $R$. battenbergiana têm sido, há várias décadas, o principal recurso econômico de algumas comunidades rurais de Gana envolvidas com seu extrativismo. Estas folhas são usadas tanto como condimento como para aromatizar óleos vegetais (Ofosu et al., 2012). Os frutos frescos de $R$. petasites e $R$. alpinia, considerados comestíveis, são comercializados com tal finalidade (Otero et al. 2000a; Macía, 2003; Frutas Raras, 2013). Conforme Macía (2003), na região de Puebla (México), a venda dos frutos de $R$. alpinia representa um ingresso econômico complementar para as famílias. No auge da colheita registrou-se o valor de US\$1,1 / Kg para este produto.

\section{CONSIDERAÇÕES FINAIS}

Renealmia é um gênero que engloba 87 espécies amplamente distribuídas na região neotropical e algumas com ocorrência também na África. No Brasil, está representado por 21 espécies, sendo registrado em todas as regiões do País.

Vários usos populares são atrelados a estas espécies, ressaltando-se os usos alimentício (4 espécies), ornamental (5 espécies) e medicinal (14 espécies). Em sua maior parte, estas indicações de uso estão associadas a $R$. alpinia (18 indicações), $R$. guianensis (11) e R. exaltata (8). As indicações de uso abrangem todas as partes do organismo vegetal, com ênfase na planta toda, rizoma e sementes. No que se refere ao uso medicinal, a maior diversidade de usos é registrada para $R$. alpinia (17), R. guianensis (11) e R. monospema (7).

Entretanto, poucas espécies inseridas no gênero Renealmia tem sido objeto de estudo quanto à sua composição química. De um total de 17 pesquisas identificadas sobre esta temática, $47 \%$ enfocavam R.alpinia, $18 \%$ eram sobre R. exaltata e $35 \%$ referiam-se a seis outras distintas espécies.
Nestas pesquisas, registrou-se relativa similaridade na composição química das espécies estudadas. Dentre os compostos comumente encontrados nestas espécies, citam-se o $\beta$-pireno e os lábdanos diterpenoides.

Igualmente escassa é a pesquisa sobre aspectos farmacológicos das espécies de Renealmia. Das 14 espécies reportadas como de uso etnobotânico, apenas quatro foram analisadas quanto as suas propriedades farmacológicas: $R$. alpinia, $R$. exaltata, $R$. nicolaoides e $R$. thyrsoidea. Interessante notar, entretanto, que há pouca coincidência entre o reportado como uso etnobotânico e os enfoques de pesquisa farmacológica sobre estas espécies. No geral, a grande maioria das indicações de etnobotânicos carecem de pesquisas que as respaldem.

A maior parte das pesquisas farmacológicas enfoca $R$. alpinia, especialmente no que se refere a confirmação das propriedades anticancerígena, antichagásica, antileishmaniose e antimalária. Estas propriedades, no entanto, não são referenciadas nas indicações de uso etnobotânico.

Em linhas gerais, há um vasto universo de conhecimento químico e farmacológico a ser desvendado no que se refere a Renealmia, mas com interessante perspectiva de aplicação no tratamento de importantes enfermidades humanas.

Outra importante lacuna de conhecimento merece atenção no sentido de otimizar o uso e aplicação das espécies de Renealmia. Apesar de haver referência de comercialização de representantes de Renealmia, tanto para fins alimentícios e ornamentais assim como medicinal, o conhecimento sobre o cultivo destas espécies é ainda escasso. A sustentabilidade do uso e conservação das espécies de interesse comercial são diretamente afetadas pela disponibilidade deste recursos em sistemas produtivos adequados e eficientes. A ampliação da base de conhecimento agronômico é, portanto, imprescindível nesta perspectiva.

\section{REFERÊNCIAS}

ACERO, L.E. Principales plantas útiles de la Amazonia Colombiana. Bogotá: Guadalupe; 1979, 263p.

ALARCÓN, J.C. In vitro propagation of Renealmia alpinia (Rottb), plant against snakebite. Vitae, v.15, n.1, p. 6169, 2008. Disponível em:< http://www.scielo.org.co/pdf/ vitae/v15n1/v15n1a08.pdf>. Acesso em 12 mar. 2013.

ALOHATROPICALS. Renealmia. Disponível em < http:// www.alohatropicals.com/renealmi.html>. Acesso em: 20 mar.2013.

ALTSCHUL, S. Drugs and foods from little-known plants. Cambridge: Harvard Univ. Press, 1973. 518p.

AYALA-SILVA, T. et al. Ornamental plant germplasm 
exploration in tropical forests of Puerto Rico. Proceedings of the Florida State Horticultural Society, v. 120, p. 4-7, 2007.

BIZERRIL, M.X.; GASTAL, M.L.A. Fruit phenology and mammal frugivory in Renealmia alpinia (Zingiberaceae) in a gallery forest of central Brazil. Revista Brasileira de Biologia, v.57, n.2, p.305-309, 1997.

BOUKOUVALAS, J.; WANG, J.X.; MARION, O.; NDZI, $B$. synthesis and stereochemistry of the antitumor diterpenoid (+)-Zerumin b. Journal of Organic Chemistry, v.71, n.18, p. 6670-6673, 2006.

CESARINO, D.D.; NEGRELLE, R.R.B. Produção de sementes e aspectos da germinação de Renealmia petasites GAGNEP. In: SIMPÓSIO BRASILEIRO DE ETNOBIOLOGIA E ETNOECOLOGIA, 9, 2012, Florianópolis. Resumos... Florianópolis: Universidade Federal de Santa Catarina, 2012. p.228.

CESARINO, D.D. Extrativismo, cultivo e comercialização de Renealmia petasites Ganep. Na APA de Guaratuba (PR). 2013. 50p. Monografia (Graduação em Ciências Biológicas). Universidade Federal do Paraná, Curitiba.

COE, F.G. Rama midwifery in eastern Nicaragua. Journal of Ethnopharmacology, v. 117, n.1, p.136157, 2008. Disponível em: <http://dx.doi.org/10.1016/j. jep.2008.01.02721>. Acesso em 5 abr. 2013.

COELHO-FERREIRA, M. Medicinal knowledge and plant utilization in an Amazonian coastal community of Maruda, Para State (Brazil). Journal of Ethnopharmacoly, v.126, p.159-175, 2009. Disponível em:<http://dx.doi. org/10.1016/j.jep.2009.07.016>. Acesso em 8 abr. 2013.

COSMEO. Mishqui panga enano, Renealmia Krukovii. Disponível em < http://www.cosmeo.com/videoTitle. cfm?\&nodeid=\&guidAssetld=A26AFB15-CAE2-4508B1A7-C11B604F6D6F>. Acesso em: 12 mar. 2013.

CRAGG, G. M.; NEWMAN, D. J.; YANG, S. S. Natural product extracts of plant and marine origin having antileukemia potential. Journal of Natural Products, v.69, n.3, p.488-498, 2006.

CUENDET, M. et al. Quinone reductase induction as a biomarker for cancer chemoprevention. Journal of Natural Products, v.69, n.3, p.460-463, 2006.

DAVIS, E.W.; YOST, J.A. The ethnomedicine of the Waorani of Amazonian Ecuador. Journal of Ethnopharmacology, v.9, p. 273-297, 1983.

DEFILIPPS, R.A.; MAINA, S.L.; CREPI, J. Medicinal plants of the Guianas (Guyana, Surinam, French Guiana). Washington (DC): Smithsonian Institute, 2004. 490p.

E*Species Tropical Seed. Gingers > Renealmia aromatica. Disponível em:< http://www.especies-seeds. com/catalog.php/especiesbotanics/dt69696>. Acesso em: 10 mar. 2013.

FERNÁNDEZ, M. et al. Evaluación de las propriedades antiofídicas del extrato etanólico y fracciones obtenidas de Renealmia alpinia (Rottb.) Mass (Zingiberaceae) cultivada in vitro. Vitae, Revista de la Faculdade de Química Farmacêutica, v.17, n.1, p. 75-82, 2010.

FRUTAS RARAS. Conheça as frutiferas nativas do Brasil e dos respectivos ecossistemas. Disponível em:<http://www.colecionandofrutas.org/nativas.htm>. Acesso em: 21 mar.2013.

GOMEZ-BELOZ, A. Plant use knowledge of the Winikina Warao: the case for questionnaires in ethnobotany.
Economic Botany, v.56, n.3, p. 231-241, 2002.

GOWRAVARAM, S.; YADAGIRI, K.; YADAV, J. S. A short and efficient synthesis of renealtins $A$ and $B$. Tetrahedron Letters, v.48, n.45, p.8065-8068, 2007. Disponível em:<DOI: 10.1016/j.tetlet.2007.09.025>. Acesso em: 20 mar. 2013.

GU, J.Q. et al. Activity-guided isolation of constituents of Renealmia nicolaioides with the potential to induce the phase Il enzyme quinone reductase. Journal of Natural Products, v.65, n.11, p:1616-1620, 2002.

HAWAIIAN TROPICAL PLANT NURSERY. Renealmia sp. Disponível em:< http://www.store. hawaiiantropicalplants.com/Renealmia-sp-55-inchsquare-pot-1490.htm>. Acesso em 12 mar. 2013.

JANNES, M. Systematics and biogeography of Renealmia I.f. (Zingiberaceae) based on nuclear and chloroplast DNA sequences. 2008. 28 p. Dissertação (Mestrado em Botânica Sistemática e Evolução). Universidade de Oxford, Inglaterra.

JUNG, E.M.; LEE, Y.R. First concise total syntheses of biologically interesting nicolaiodesin $\mathrm{C}$, Crinatusin $\mathrm{C}_{1}$, and Crinatusin $\mathrm{C}_{2}$. Korean Chemical Society, v.29, n.6, p.1199-1204, 2008.

JUSTO, B.H.; MOTA, D.S.; COELHO, S. A etnobotânica e o conhecimento popular: estudos de caso na cidade de Sorocaba, SP, Brasil. In: CONGRESSO DE MEIO AMBIENTE DA AUGM, 6, 2009. São Carlos. Anais... São Carlos, AUGM, 2009. p.1-15. Disponível em:< http:// www.ambiente-augm.ufscar.br/uploads/A3-097.pdf>. Acesso 2m 15 mar. 2013.

KANG, Y.; PEZZUTO, J.M. Induction of quinone reductase as a primary screen for natural product anticarcinogens. Methods in Enzymology, v.382, p.380-414, 2004.

KAPLAN M.A.C. et al. The stereochemistry of ledol from Renealmia chrysotrycha: an NMR study. Phytochemistry, v. 55, n.7, p.749-753, 2000.

KRESS, W.J. The phylogeny and classification of the Zingiberales. Annals of the Missouri Botanical Garden, v. 77: 698-721, 1990.

LANS, C.; HARPER, T.; GEORGES, K.; BRIDGEWATER, $E$. Medicinal and ethnoveterinary remedies of hunters in Trinidad. BMC Complementary and Alternative Medicine, n.1, p.1-17, 2001. Disponível em:http:// www.biomedcentral.com/1472-6882/1/10. Acesso em 12 mar.2013.

LECLERCQ, P. A. et al. Aromatic Plant Oils of the Peruvian Amazon. Part 2. Cymbopogon citratus (DC) Stapf., Renealmia sp., Hyptis recurvata Poit. and Tynanthus panurensis (Bur.) Sandw. Journal of Essential Oil Research, v.12, n.1, p.14-18, 2000. Disponível em:<DOI: 10.1080/10412905.2000.9712030>. Acesso em 22 mar. 2013.

LOGNAY, G.; MARLIER, M.; HAUBRUGE, E.; TREVEJO, E. Study of the lipids from Renealmia alpinia (Rott) Maas. Grasas y Aceites, v.40, n.6, p. 351-355, 1989.

LOGNAY, G, MARLIER M, SEVERIN M, HAUGRUGE E, GIBON V, TREVEJO E. On the characterization of some terpenes from Renealmia alpinia Rottb. (Maas) Oleoresin. Flavour and Fragance Journal, v.6, p.8791, 1991.

LOPES, C.V.G. O conhecimento etnobotânico da comunidade quilombola do Varzeão, Dr. Ulysses (PR): no contexto do desenvolvimento rural

Rev. Bras. PI. Med., Campinas, v.17, n.2, p.274-290, 2015. 
sustentável. 2010. 162 p. Dissertação (Mestrado Agronomia). Universidade Federal do Paraná, Curitiba.

LUZ A. I. R. et al. Essential Oils of Some Amazonian Zingiberaceae, 3. Genera Alpinia and Renealmia. Journal of Natural Products, v.47, n.5, p.907-908, 1984. Disponível em:<DOI: 10.1021/np50035a037> Acesso em: 22 mar. 2013.

MAAS, P.J.M. Renealmia (Zingiberaceae- Zingiberoideae). Costoideae (Additions) (Zingiberaceae). Flora Neotropica Monograph, v.18, p.1-218, 1977.

MAAS, P.J.M.; MAAS, H. Notes on New World Zingiberaceae: 3.some new species in Renealmia. Notes from the Royal Botanical Garden, Edinburgh, v. 44, p. 237-248, 1987.

MAAS, P.J.M.; MAAS, H. Notes on New World Zingiberaceae: 4. some new species of Costus and Renealmia. Notes from the Royal Botanical Garden, Edinburgh, v. 46, p. 307-320,1990.

MAAS, P., MAAS, H. Zingiberaceae in Lista de Espécies da Flora do Brasil. Disponível em :<http://floradobrasil. jbrj.gov.br/2012/FB110707>. Acesso em 08 abr. 2013.

MACÍA, M. J. Renealmia alpinia (Rottb.) Maas (Zingiberaceae): planta comestible de la sierra norte de Puebla (México). Anales del Jardín Botánico de Madrid, v. 60, n.1, p.183-187, 2003.

MAIA, J. G. S. et al. Essential oil composition of Renealmia alpinia (Rottb.) Maas. In: SIMPÓSIO BRASILEIRO DE ÓLEOS ESSENCIAIS, 4, 2007, Fortaleza. Disponível em:< http://www.ivsboe.padetec.ufc.br/CDSimposio/ quimicaeatividadesbiologicasdosoleosessenciais/ Resumo_MaiaJGS1.pdf>. Acesso em: 21 mar. 2013.

MAJUMDAR, I.D. et al. Synthetic cyclohexenyl chalcone natural products possess cytotoxic activities against prostate cancer cells and inhibit cysteine cathepsins in vitro. Biochemical and Biophysical Research Communications, v.416, n.3-4, p.397-40216, 2011.

MARCHESE, R. M. Atividade de constituintes micromoleculares de $R$. alpinia (Rottb.) Maas (Zingiberaceae) sobre Leishmania (Leishmania) chagasi. 167p. 2009. Dissertação. (Mestrado Ciências da Saúde) - Universidade de Brasília, Brasília.

MARTÍNEZ ALFARO M.A. et al. Catálogo de plantas útiles de la Sierra Norte de Puebla, México. México D.F: Instituto de Biología, Universidad Nacional Autónoma de México. Cuadernos del Instituto de Biología, v. 27, p.1-303, 1995.

MERRIAM-WEBSTER. Renealmia. Disponível em: <http:// www.merriam-webster.com/dictionary/renealmia>. Acesso em: 19 mar. 2013.

MICELI, F.A.G. et al. Optimization of R. mexicana (Klotzsch ex. Petersen) cultivation in vitro. In Vitro Cellular \& Developmental Biology - Plant , v.44, n. 1, p. 33-39, 2008.

MILENAR TERAPIAS. Pacová - Renealmia brasiliensis. Disponível em: < http://www.lojamais.com.br/Loja/ Emp_MostraProd.aspx?codProduto $=376805 \&$ code $m p=5120>$. Acesso em: 21/03/2013.

MILLIKEN, W.; ALBERT, B. The use of medicinal plants by the Yanomami Indians of Brazil. Economic Botany, v. 50, n.1, p.10-25, 1996.

MINAS GERAIS. Deliberação do Conselho Estadual de Política Ambiental - COPAM n 85, de 21 de outubro de 1997. Aprova a lista das espécies ameaçadas de extinção da flora do Estado de Minas Gerais. Diário do Executivo [do Estado de Minas Gerais], 30/10/1997.

MINAS GERAIS. Deliberação do Conselho Estadual de Política Ambiental - COPAM n 367, de 15 de dezembro de 2008. Aprova a lista das espécies ameaçadas de extinção da flora do Estado de Minas Gerais. Diário do Executivo [do Estado de Minas Gerais], 17/12/2008.

MONTOSO GARDENS. Renealmia occidentalis (Zingiberaceae). Disponível em <http://www. montosogardens.com/renealmia_occidentalis.htm>. Acesso em 21 mar.2013.

NÚÑEZ, V. et al. Neutralization of the edema-forming, defibrinating and coagulant effects of Bothrops asper venon by extracts of plants used by healers in Colombia. Brazilian Journal of Medical and Biological Research, v.37, p.969-977, 2004a.

NÚÑEZ, V. et al. Inhibition of the toxic effects of Lachesis muta, Crotalus durissus cumanensis and Micrurus mipartitus snake venoms by plant extracts. Pharmaceutical Biology , v. 42, n.1, p.49-54, 2004b.

OFOSU, I.W.; OPPONG, S.Y.; ODURO, I. Optimization of incorporation conditions of Renealmia battenbergiana extract in refined bleached deodorized (RBD) palm olein. Food and Nutrition Sciences, v.3, p.1976-1983, 2012.

OSPINA-GONZÁLES, J.C. Adaptaciones morfoanatómicas de especies simpátricas de Renealmia (Zingiberaceae). Informe final de actividades realizadas Beca RLB2010-P06, 2011. 6p. Disponível em:< http://www.rlb-botanica.org/Varios/ Informe\%20final\%20Juan\%20Camilo\%200spina.pdf>. Acesso em 03 abr. 2013

OTERO, R. et al. Snakebites and ethnobotany in the northwest region of Colombia. Part I: Traditional use of plants. Journal of Ethnopharmacology, v.71, n.3, p.493-504, 2000a. Disponível em:< http://www. sciencedirect.com/science>. Acesso em 03 abr. 2013.

OTERO R. et al. Snakebites and ethnobotany in the northwest region of Colombia, Part II: Neutralization of letal and enzymatic effects of Bothrops atrox venom. Journal of Ethnopharmacology, v.71, n.3, p.505-511, 2000b. Disponível em:< http://www.sciencedirect.com/ science>. Acesso em 03 abr. 2013.

OTERO, R. et al. Snakebites and ethnobotany in the northwest region of Colombia, Part III: Neutralization of the haemorrhagic effect of Bothrops atrox venom. Journal of Ethnopharmacology, v.73, n.1-2, p.233241, 2000c. Disponível em:< http://www.sciencedirect. com/science>. Acesso em 03 abr. 2013.

PATIÑO, A. C. et al. Efecto inhibitorio de extractos de Renealmia alpinia Rottb. Maas (Zingiberaceae) sobre el veneno de Bothrops asper (mapaná). Biomédica: Revista del Instituto Nacional de Salud, v. 32, n. 3, p 365-374, 2012.

PLANTAMED. Índice de Plantas e Ervas Medicinais por Nomes Científicos. Disponível em < http://www. plantmed.com.br/>. Acesso em 21/3/2013.

RAINFOREST Conservation Fund. Renealmia spp. (Mishqui panga). Disponível em <http://www. rainforestconservation.org/AGROFORESTRYETHNOBOTANY/AGROFORESTRY-ETHNOBOTANY/ RENEALMIA-SPP-MISHQUI-PANGA> Acesso em 20/03/2013.

RAMIANDRASOA F. et al. Labda-8(17),12-diene-

Rev. Bras. Pl. Med., Campinas, v.17, n.2, p.274-290, 2015. 
15,16-dial, a constituent of Renealmia guianensis (Zingiberaceae). Plantes Medicinales et Phytotherapie v.20, n.3, p.227-230, 1986

RANGEL, E.T. Atividade antiprotozoária, antifúngica e citotóxica de extratos de plantas do bioma Cerrado, com ênfase em Leishmania (Leishmania) chagasi. 131p. 2010. Tese (Doutorado em Ciências da Saúde) Universidade de Brasília, Brasília.

RENNER, S. Plant dispersal across the tropical Atlantic by wind and sea currents. International Journal of Plant Sciences, v.165, n.4 supl., p.S23-S33, 2004.

SACHAVACAY. Plantas maestras. Disponível em http:<www.sachavacay.org/plantas-maestras.html>. Acesso em 18/03/2013.

SANTOS, A.F.; SANT'ANA; A.E.G. The molluscicidal activity of plants used in Brazilian folk medicine. Phytomedicine, v. 6, n. 6, p.431-438, 2000.

SÄRKINEN, T.E. et al. Recent oceanic long-distance dispersal and divergence in the amphi-Atlantic rain forest genus Renealmia L.f. (Zingiberaceae) Molecular Phylogenetics and Evolution, v.44, n.3, p.968-980, 2007.

SCHULTES, R.E.; RAFFAUF, R.F. The healing forest: medicinal and toxic plants of the northwest Amazonia. Portland: Dioscorides Press, 1990. 484p.

SEKIGUCHI M. et al. Pacovatinins A-C, new labdane diterpenoids from the seeds of Renealmia exaltata. Journal of Natural Products, v.64, n.8, p.1102-6, 2001.

SEKIGUCHI M. et al. Renealtins A and B, New diarylheptanoids with a tetrahydrofuran ring from the seeds of Renealmia exaltata. Journal of Natural Products, v.65, n.3, p.375-376, 2002.

SIES, H. \& PACKER, L. Quinones and quinones enzymes. London: Academic Press, 2004 421p.

SILVA, F.M. Potencial antifúngico de extratos de plantas medicinais do cerrado brasileiro. 2008. 222p.. Dissertação (Mestrado em Ciências Médicas) Universidade de Brasília, Brasília, 2008.

SILVA, R.B.L. A etnobotânica de plantas medicinais da comunidade quilombola de Curiaú, MacapáAP, Brasil. 2002. 172p. Dissertação (Mestrado em Agronomia) - Universidade Federal Rural da Amazônia, Belém 2002.

SOUZA, V.C. \& LORENZI, H. Botânica Sistemática: guia ilustrado para identificação das famílias de Angiospermas da flora brasileira, baseado em APGII. São Paulo: Nova Odessa/Instituto Plantarum, 2005. 640p.

STANDLEY, P.C.; STEYERMARK, J.A. Flora of Guatemala. Chicago: Chicago Natural History Museum, 1952. $432 \mathrm{p}$

STEVENS, P.F. Angiosperm Phylogeny Website. Disponível em: <http://www.mobot.org/MOBOT/ research/APweb/>. Acesso em 02/03/2013.

THE PLANT LIST. Renealmia. Disponível em:< http:// www.theplantlist.org/>. Acesso em 20 mar 2013.

TROPICAL FLOWER FARM. Renealmia occidentalis.
Disponível em <http://www.tropicalflowerfarm.com/ catalog/ginger-renealmia-occidentalis.html> Acesso em 22 mar. 2013.

TROPICOS. Renealmia. Disponível em:< http://www. tropicos.org/>. Acesso em: 20 mar. 2013.

TROPILAB INC. Renealmia exaltata - masusa. Disponível em: http://www.tropilab.com/masusa.html. Acesso em 22/03/2013.

USHER, G. Dictionary of plants used by man. New York: Hafner Press, 1974. 619p.

VALADEAU, C. et al. Medicinal plants from the Yanesha (Peru): Evaluation of the leishmanicidal and antimalarial activity of selected extracts. Journal of Ethnopharmacology, v. 123, n. 3, p. 413-422, 2009.

VAN ANDEL, T. The diverse uses of fish-poison plants in Northwest Guyana. Economic Botany, v.54, n.4, p.500-512, 2000.

VAN ANDEL, T.; HAVINGA, R. Sustainability aspects of comercial medicinal plant harvesting in Suriname. Forest Ecology and Management, v.256, p. 15401545, 2008.

VILA VERDE, G.M.; PAULA, J.R; CANEIRO, D.M. Levantamento etnobotânico das plantas medicinais do cerrado utilizadas pela população de Mossâmedes (GO). Revista Brasileira de Farmacognosia, v. 13, supl., p. 64-66, 2003.

VILLALOBOS CONTRERAS, G. Plantas comestibles en dos comunidades de la Sierra Norte de Puebla: Xochitlán de Vicente Suárez y Zapotitlán de Méndez. 1994. 315p. Monografia (Graduação em Biologia) - Universidad Nacional Autónoma de México, México, D.F.

WOHLMUTH, H. et al. Diarylheptanoid from Pleuranthodium racemigerum with in vitro prostaglandin e inhibitory and cytotoxic activity. Journal of Natural Products, v.73, n.7 p.43-746, 2010.

XAVIER, T. B. et al. Avaliação da atividade antiparasitária de Renealmia exaltata frente a Haemonchus contortus em ovinos. In: Congresso da Sociedade Paulista de Parasitologia, 4., 2008, Campinas. Resumos... Disponível em:< http://www2.ib.unicamp.br/branco/ parasit/spp/VI\%20congresso/fscommand/resumos/ tratamento/TRAT11_Thalyta_Baldim_Xavier2.pdf>. Acesso em: 21 mar. 2013.

XU, H.X.; DONG, H.; SIM, K.Y. Labdane diterpenes from Alpinia zerumbet. Phytochemistry v.42, n.1, p. 149151, 1996.

YANG, S.W. et al. A new labdane diterpene from Renealmia alpinia collected in the Suriname Rainforest. Journal of Natural Products, v.62, n.8, p.1173-1174, 1999.

ZARONI, M. et al. Qualidade microbiológica das plantas medicinais produzidas no Estado do Paraná. Revista Brasileira de Farmacognosia, v.14, n.1, p.29-29, 2004.

ZHOU, B. et al. Bioactive labdane diterpenoids from $R$. alpinia collected in the Suriname Rainforest. Journal of Natural Products, v.60, n.12, p.1287-1293, 1997. Disponível em:<http://dx.doi.org/10.1021/np970233c>. Acesso em: 15 mar. 2013. 